\title{
Contribution of non-native galliforms to annual variation in biomass of British birds
}

\author{
Tim M. Blackburn (1D) Kevin J. Gaston
}

Received: 30 July 2020 / Accepted: 4 January 2021 / Published online: 23 January 2021

(C) The Author(s) 2021

\begin{abstract}
Millions of individuals of two species of non-native galliform birds, the Common Pheasant (Phasianus colchicus) and Red-legged Partridge (Alectoris rufa) are released into the British countryside annually in late summer, supplementing established breeding populations of these two species. The biomass of birds involved in these releases has been compared to the British breeding bird biomass. However, the validity of this comparison is compromised because the biomass of wild birds varies across the year due to reproduction, mortality and migration. How the biomass of Common Pheasants and Redlegged Partridges compares to that of other British bird species in late summer, or across the whole year, is
\end{abstract}

Supplementary material The online version contains supplementary material available at (https://doi.org/10.1007/ s10530-021-02458-y) contains supplementary material, which is available to authorized users.

T. M. Blackburn ( $\square)$

Centre for Biodiversity and Environment Research, Department of Genetics, Evolution and Environment, University College London, Gower Street,

London WC1E 6BT, UK

e-mail: t.blackburn@ucl.ac.uk

T. M. Blackburn

Institute of Zoology, Zoological Society of London, Regent's Park, London NW1 4RY, UK

\section{K. J. Gaston}

Environment and Sustainability Institute, University of Exeter, Penryn, Cornwall TR10 9FE, UK currently unknown. Here, we produce estimates of how British bird biomass varies across the year, to assess the contribution of the two non-native galliforms to this variation. We show that overall British bird biomass is probably lowest around the start of the breeding season in April, and peaks in late summer and autumn. We estimate that around a quarter of British bird biomass annually is contributed by Common Pheasants and Red-legged Partridges, and that at their peak in August these two species represent about half of all wild bird biomass in Britain.

Keywords Non-native $\cdot$ Biomass $\cdot$ Birds $\cdot$ Common pheasant · Great Britain · Red-legged partridge

\section{Introduction}

The native British bird assemblage is supplemented annually each autumn by the release of large numbers of non-native galliforms of two species, the Common Pheasant (Phasianus colchicus) and Red-legged Partridge (Alectoris rufa), as quarry for hunters. Estimates from 2016 place the numbers of individuals released at 47 million (95\% confidence intervals 39-57 million) Common Pheasants and 10 million (95\% confidence intervals 8.1-13 million) Red-legged Partridges (Aebischer 2019). This practice of releases has a long history in Britain, where populations of both species 
are naturalised, but there is evidence that the size of these releases has increased dramatically in recent decades. For example, the annual number of Common Pheasants released has grown roughly seven-fold since the 1960s (Robertson et al. 2017). This change is motivated in part by the money that can be made from commercial Pheasant shoots (Avery 2019), where people pay on the basis of the number of birds shot, and in part by the collapse of the population of the native Grey Partridge (Perdix perdix), which declined by $88 \%$ in the 40 years prior to 2006 (Baillie et al. 2009). The releases are facilitated by large-scale breeding and rearing of birds on shooting estates and in commercial game farms, supplemented by imports of eggs and poults, largely from France. In 2019, imports comprised more than 5 million live Common Pheasants and almost 20 million eggs, and more than 2 million live Red-legged Partridges (Madden and Sage 2020).

The release of non-native species is a concern because of their potential negative impacts on native species. Amongst other things, non-native species may compete with, consume, vector diseases to, or hybridise with native species, causing changes in native species richness and abundance (Vilà et al. 2011; Pyšek et al. 2012; Cameron et al. 2016; Gallardo et al. 2016) and hindering ecosystem functioning and provision of ecosystem services (Gaertner et al. 2014; Vilà and Hulme 2017). In extreme cases, non-native species cause the extirpation or extinction of native species (Pyšek et al. 2020), and indeed are associated with the global extinction of more species since 1500AD than any other recorded cause (Blackburn et al. 2019). Pheasants have been reported to compete with native species in their non-native range in the United States (Lever 2005; Holt et al. 2010), and to act as a reservoir for a shared parasite that could be contributing to declines in native Grey Partridge populations in the UK (Tompkins et al. 2000; but see Sage et al. 2002). Pheasants have a catholic diet, consuming a wide range of plant and animal material. They have been shown to damage vegetation in the vicinity of release pens (Sage et al. 2005; Capstick et al. 2019). Invertebrate communities differ in areas of high and low Pheasant releases (Neumann et al. 2015), and there is lower ground-active invertebrate biomass in areas where Pheasants are released (Pressland 2009). Pheasants may also constitute a major food source for native predators, elevating predator populations (Pringle et al. 2019) and imposing apparent competition effects on native prey species. Finally, non-native galliforms exert indirect effects on the native British biota through habitat and predator management by gamekeepers and land owners aimed at benefitting these species. This management is likely to increase populations of some other species, but will also cause declines (Larkman et al. 2015). While there is currently more evidence for negative impacts than for positive (Mason et al. 2020), the overall net ecological effects of non-native galliforms and their management on native British wildlife cannot yet be reliably determined (Madden and Sage 2020).

Most studies of the ecological impacts of Common Pheasants and Red-legged Partridges have focussed on relatively local-scale ecological interactions (although see Pringle et al. 2019). Additional insights may be gained from a macroecological approach, by considering the relationship of these non-native galliforms to general large-scale patterns in the abundance and/or distribution of native species. In this context, Common Pheasants in particular are notable for their contribution to the biomass of the British avifauna, and to the energy consumed by its constituent species. For example, data from 2013 (Musgrove et al. 2013) showed that there was a greater breeding biomass of Common Pheasants (3740 tonnes, or $15.6 \%$ of the total British breeding bird biomass) than of any other species except the Woodpigeon (Columba palumbus; 5088 tonnes, or $21.2 \%$ of the total) (Blackburn and Gaston 2018). Common Pheasants also ranked second amongst British breeding birds in terms of population energy use. The consequences of so much biomass and energy use for the native British flora and fauna are likely to be substantial, unless Common Pheasants are using resources that otherwise would not be consumed, or are not themselves consumed by native species (see Discussion).

The estimates of biomass and energy use discussed so far (from Blackburn and Gaston 2018) are based on breeding population sizes. Yet, the number of Common Pheasants released into Britain in autumn is almost 10 times the size of the species' breeding population, while the equivalent for Red-legged Partridges is 40 times. The amount of resources appropriated by just the Pheasants released seems likely to dwarf that used by any other species in the British avifauna in autumn-indeed, the figures in Blackburn and Gaston (2018) imply that the biomass 
of Pheasants released in autumn is roughly equal to the total breeding biomass of all other species in the British avifauna combined. However, at present, how the biomass of Common Pheasants and Red-legged Partridges in autumn compares to that of other British bird species is not known, a calculation thwarted because there are not estimates of how bird biomass varies across the year. The biomass of British breeding species increases over summer due to the growth and recruitment of individuals from reproduction, a proportion of which will survive at least until the following breeding season. Autumn also brings the arrival of substantial numbers of individuals of various species that winter in Britain, many of which are relatively large-bodied wildfowl and waders, which will bolster resident bird biomass. However, autumn also sees the departure of many summer visitors, which return to their wintering grounds further south. Some individuals of 'resident' species (i.e. those present in Britain year-round) also leave to winter elsewhere, while other individuals of these same species arrive to bolster local populations in Britain. Yet other species take more than a year to reach maturity (e.g. gulls), such that estimates of their breeding population sizes do not include many (probably most) of the individuals present in Britain in the breeding season. Overall, then, how the biomass of Common Pheasants and Red-legged Partridges compare to other birds in Britain in autumn, and indeed across the year, is currently unclear.

Here, we estimate how the biomass of British birds varies across the year, so that we can assess the likely addition to this biomass due to within-year variation in the Common Pheasant and Red-legged Partridge populations (given the great preponderance of Common Pheasants in releases, and their larger body mass, we largely focus on this species). We start with an assumption of breeding population sizes based on the most recent available information from the fourth report of the Avian Population Estimates Panel (APEP4; Woodward et al. 2020), and then present simple estimates for how numbers of free-flying birds change month by month due to reproduction and annual migration. We also estimate the numbers of non-breeding birds for species that take more than a year to reach maturity. We then compare annual variation in Pheasant and Partridge biomass to that of the rest of the species in Britain. We show that the contribution of Common Pheasants and Red-legged
Partridges to overall breeding biomass is at its lowest in the breeding season, and at its highest in the last quarter of the year.

\section{Methods}

APEP4 (Woodward et al. 2020) provided breeding population size estimates for 226 species of British birds, and winter population size estimates for 104 species (including 27 species without breeding populations). All estimates were converted into number of individuals by doubling those presented in terms of number of breeding pairs, females, males or territories, following the methods used in Blackburn and Gaston (2018). Thus, we convert the APEP4 figures of 2.3 million breeding female Common Pheasants and 72,500 Red-legged Partridge territories into estimates of 4.6 million and 145,000 breeding birds, respectively. Unlike in this previous paper, we included seabirds in the biomass estimates. Some seabird species that breed in Britain and that have a large wintering biomass, pass the winter to a greater or lesser degree in coastal waters. There they feed alongside a range of species, such as ducks, cormorants, and grebes, that use inshore and offshore waters to different extents throughout the year. Including seabirds allows us more easily to track annual variation in biomass across the whole British bird assemblage, but excluding them would largely serve to increase the relative contributions of nonnative galliforms to biomass in any given month.

We next derived rough estimates of how the population sizes of these species varied from month to month across the year. To produce these estimates, we collated information on adult mortality (survival) rates, mean date of first nesting, clutch size, number of clutches per year, time taken to fledge (nesting plus fledging periods), and average breeding success (proportion of eggs laid that successfully fledged), mainly from the BTO website (Robinson 2005), but with some data (principally for average breeding success) coming from Birds of the Western Palearctic (Cramp 1985, 1988, 1992; Cramp and Perrins 1993, 1994a, b; Cramp and Simmons 1977, 1980, 1983).

We began by assuming that the breeding population size provided by Woodward et al. (2020) was, for most species, the number of breeding birds present in April. For resident British species with minimal immigration 
or emigration (e.g. Crested Tit Parus major), we further assumed that the population size varied across the year because of the death of adults (as described below) and the fledging and subsequent death of juveniles. New birds were added to the population at a date (i.e. in a month of the year) that depended upon the mean date of first nesting, the time taken to fledge (nesting plus fledging periods), and the number of clutches per year. The number of new birds added in each month was calculated from the average clutch size and the average breeding success for a species (Fig. 1a).

We then assumed that annual adult survival, M (\%), entailed the loss of individuals at a constant rate across the following 12 months, so that by the following April M\% of breeding adults from the previous April were still alive. We also assumed that breeding populations are neither increasing nor decreasing. This assumption will not be true for many species in the British avifauna, but annual changes will in most cases be small, and even changing populations will
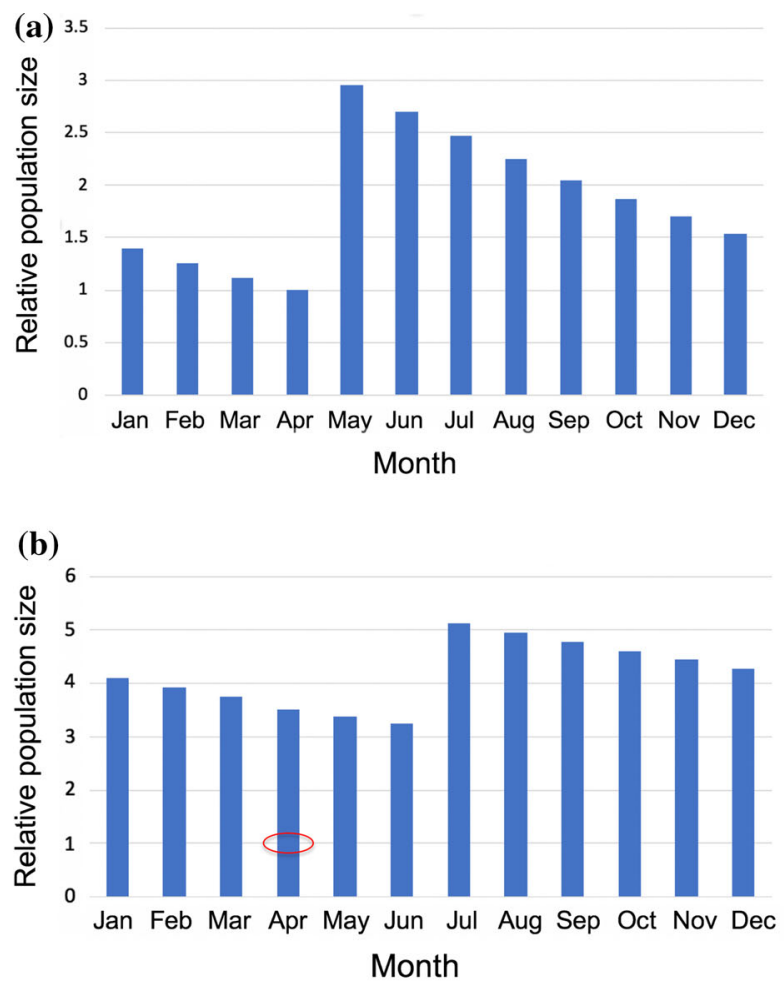

Fig. 1 Exemplar plots showing how population size varies across the year, relative to the breeding population size in April (=1), for a Crested Tit (Lophophanes cristatus), b Canada Goose (Branta canadensis), c Barnacle Goose (B. leucopsis), fluctuate between good and bad years. Assuming a constant stable British bird population greatly simplifies the calculations, and means that the $100-\mathrm{M} \%$ of adults dying in each year were exactly replaced by recruits to the breeding population from reproduction. We assumed that the new recruits added to the population through reproduction died (and hence were removed from the population) at an exponential rate, subject to the assumptions about recruitment described below. Temporal variation in post-fledging mortality is not well known, but studies of U.K. passerines suggest that a high proportion (40-70\%) of fledglings die in their first month or two out of the nest (Siriwardena et al. 2000).

Different bird species take different times to reach maturity. If time to maturity is $\mathrm{t}$, we assumed that the recruits died at an exponential rate such that the number remaining to breed in April of year $t$ was $100-\mathrm{M} \%$ of the original breeding population. For example, the Great Tit Parus major takes 1 year to reach maturity, and has an adult survival rate (based on
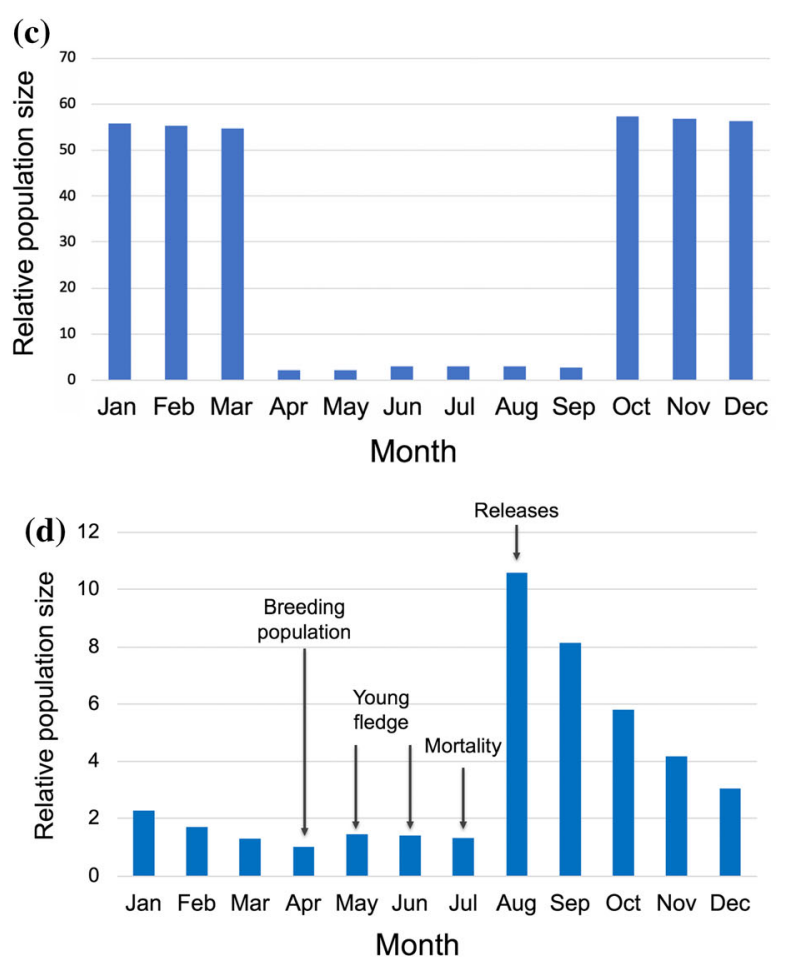

and $\mathbf{d}$ Common Pheasant (Phasianus colchicus). The red ellipse in (b) indicates the breeding population size, to show that the population size estimate in April includes many non-breeding individuals 
data from the British Trust for Ornithology (BTO) website; see below) of 54.2\%. For this species, birds fledged in year 0 were assumed to die at a rate that leaves a number equal to $45.8 \%$ of the breeding population alive in April of year 1. The total population size of this species varies from month to month depending on this pattern of birth and death, but returns to the breeding population size estimate from Woodward et al. (2020) in April. For species that take longer than one year to reach maturity, we assumed that the process of juvenile recruitment and death spans this period of maturation. Thus, for example, the Canada Goose Branta canadensis takes 3 years to reach maturity, and has an adult survival rate of $72.4 \%$. For this species, birds fledged in year 0 die at a rate that leaves a number equal to $27.6 \%$ of the breeding population alive in April of year 3. However, in addition to the breeding population, in any given year there are also 1 and 2-year old geese in the population. The total population size in April is then the sum of these maturing birds and the breeding population size from Woodward et al. (2020). The total Canada Goose population size (and likewise also the Canada Goose biomass) in April is therefore larger than just the breeding population (Fig. 1b).

Many species in the British avifauna are present entirely or overwhelmingly as either summer or winter visitors. For summer migrants, we assumed that the entire breeding population arrived in April (or in a few cases May), and left in September. The imperative to breed means that these assumptions are probably reasonable-individuals will tend to arrive largely simultaneously, at least on the time-scale of months. We then assumed that the size of the population in Britain varied between the months of arrival and departure as described for resident species (adult mortality, fledgling recruitment and subsequent mortality, and no variation in breeding population size from year to year).

We used Balmer et al. (2013) and Wernham et al. (2002) to identify when populations of winter visitors to Britain generally arrived and departed. We typically assumed that the entire wintering population arrived together and early on, and departed together and late, in the normal wintering period. This is likely to overestimate numbers present in autumn and spring, as the arrival and departure of individuals in most wintering species is more flexible than for breeding species, may depend on weather in Britain and elsewhere, and spans a period of several weeks. During winter, we assumed that the population decreased following adult mortality rates, and from the wintering population size estimated by Woodward et al. (2020).

Some species breed and winter commonly in Britain, with the wintering population bolstered by immigrants from continental Europe, or with the wintering population reduced by emigrants. Estimating population changes over the year in these species is more difficult. Where Woodward et al. (2020) provided separate breeding and wintering population size estimates, we assumed that the breeding population varied across the year as described for species with minimal immigration or emigration, and then scaled the population size outside the breeding season (i.e. September to April) on the basis of the reported wintering population size, assuming this population size was reached in December and January (Fig. 1c). In some cases, this meant assuming emigration in autumn and immigration in March, and in other cases the reverse. These estimates are crude, but in fact there are relatively few species of this sort, and their biomass is generally small relative to primarily resident species.

Finally, for Common Pheasant and Red-legged Partridge, we assumed that annual variation in the breeding population followed the methods described above for resident species. For Common Pheasants, we used the figures in Robertson (1991) to produce an estimate of a single fledged juvenile per female, which is added to the population at the end of May, followed by exponential mortality of these first-year birds through to the following breeding season. Coupled with adult mortality, this suggests that the breeding population is not self-sustaining. However, the resident population is supplemented by the numbers released in summer, which we assumed were as recorded by GWCT (2018): 43 million Common Pheasants. These are slightly lower than the most recent figures (Aebischer 2019), but estimates of release sizes are likely to have high uncertainty, and these are closer to the centre of the current likely range (see below). We assumed that all the Pheasants were released in August, and that 25\% of these died before the start of the shooting season on 1st October, as estimated by the Game and Wildlife Conservation Trust (GWCT). GWCT also estimates that $16 \%$ of released Pheasants survived until after the shooting 
season ends on 1st February (https://www.gwct.org. uk/research/species/birds/common-pheasant/fate-ofreleased-pheasants/). We therefore assumed, starting from October, that just over two-thirds of the releases alive in one month had died by the next month, and that this mortality rate continues through to the start of the next breeding season. This results in around 2 million birds surviving to contribute to the next year's breeding population, bringing that back to 4.6 million birds. For Red-legged Partridges, we assumed that birds were released in July, and that $25 \%$ of these died before the start of the shooting season on 1st September. We then assumed that, starting from September, half of the releases alive in one month had died by the next month, with none of the birds left alive in March surviving to April. In fact, many Pheasants and Partridges are likely to have been released before August and July, respectively, and so our estimates of the overall contribution of these birds to annual British bird biomass is probably conservative.

The calculations described were used to produce estimates of the proportion of the British breeding population size (from APEP4) present in Britain in each month of the year. We then used these proportions to calculate the British population size for each species in each month. We used estimates of average body mass (from Gaston and Blackburn 2000; Dunning 2007) to calculate the biomass for each species in each month, assuming no annual variation in average mass. The mass for Common Pheasant in our data originated from Cramp and Simmons (1977), and at $850 \mathrm{~g}$ is low relative to estimates from other sources (female mass of $951 \mathrm{~g}$ from Storchova and Horak (2018), mean mass of $1.135 \mathrm{~kg}$ from Dunning (2007)). We may therefore underestimate Common Pheasant biomass, although probably not by much. Those birds added to the population through reproduction in spring will not be fully grown, while the same will be true of the reared birds released in summer (the vast majority of the population), which do not attain full adult body mass until the autumn.

We produced these intra-annual biomass estimates for 81 of the 253 species breeding or wintering in Britain as listed by APEP4 (Woodward et al. 2020). These 81 species represent $93.4 \%$ of the total breeding biomass, as many of the species breeding in Britain have small breeding population sizes, small body masses, or both, and so contribute negligibly to overall biomass (Fig. 2). Indeed, the top four species in our analysis account for more than 50\% of British breeding biomass, while the species with the most biomass missing from our analysis (Common Buzzard Buteo buteo) accounts for just over $0.5 \%$. The species considered also included those with large wintering biomasses (principally wildfowl and waders) to ensure that the winter avifauna of Britain was not underrepresented: $82 \%$ of the biomass of species with winter population estimates given by Woodward et al. (2020) is included in our 81 species, although most winter biomass is actually in resident species without separate winter population size estimates (and $>90 \%$ of our estimate of total January biomass comes from resident species). The data used are given in an Online Appendix.

While there is undoubtedly uncertainty in all of the biomass estimates used in our analysis, the most significant is likely to relate to the number of Common Pheasants and Red-legged Partridges released in autumn. Madden and Sage (2020) highlight that the usually quoted figures (e.g. Aebischer 2019; Avery 2019) include high levels of uncertainty, because nonnative galliform releases are not formally documented. They therefore explored a range of different methods of estimating release numbers, including the APHA poultry register and import records, in addition to the National Gamebag Census (on which the figures in Aebischer (2019) were calibrated). These multiple approaches suggest that numbers released could lie anywhere in the range 10-57 million Pheasants, and 1-13 million Partridges. We therefore re-ran our analyses with the lower and upper numbers in this range, to assess how the maximum likely uncertainty affects our conclusions.

\section{Results}

The total biomass of the breeding population of British birds in April estimated from the data in APEP4 is 23,844 tonnes, divided amongst 161,211,593 individuals. These numbers are very similar to those of the previous estimates in APEP3 (23,964 tonnes and $158,318,942$ birds). Our estimates of annual variation in British bird population produce a total of 33,484 tonnes of birds in April, or around 10,000 tonnes more than the estimate of breeding population biomass. The difference arises because of the additional biomass of non-breeding individuals of species that take several 


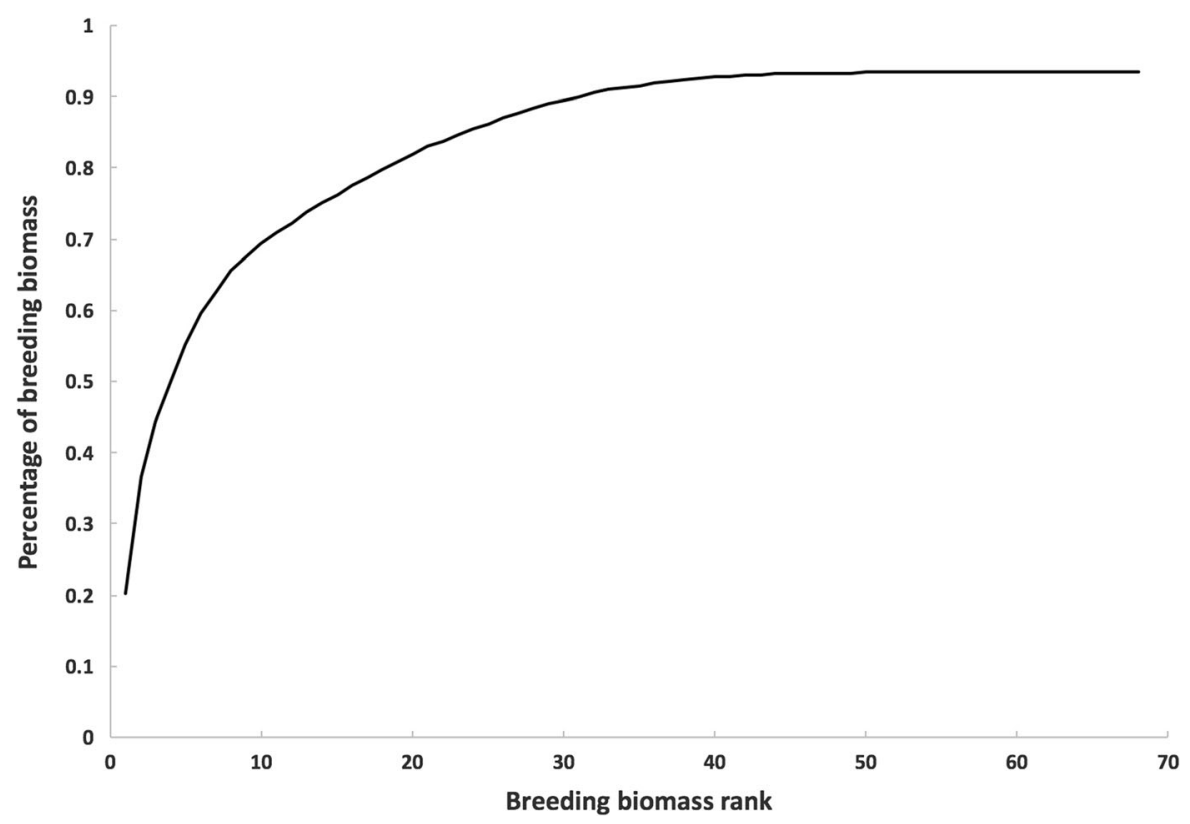

Fig. 2 The cumulative British breeding bird biomass accounted for by the 81 species in our analysis, ranked from highest to lowest in terms of breeding biomass

years to mature, and of wintering individuals of some species that (we assume) have not yet departed for their breeding grounds. The Common Pheasant contributes approximately 3,910 tonnes to the April total (11.7\%), and the Red-legged Partridge around 63.6 tonnes $(0.2 \%)$. This leaves 29,510 tonnes of British bird biomass in April that does not derive from these two particular non-native species, of which 19,870 tonnes is breeding bird biomass.

Our estimates of monthly variation in bird biomass suggest that the start of the breeding season (April) is actually the low-point of annual variation (Fig. 3a). Biomass increases from then throughout the summer mainly due to the addition of fledglings, and then spikes dramatically at 84,798 tonnes in August. This spike is largely due to the release of 43 million Common Pheasants; British bird biomass is at its highest in July with the Common Pheasant excluded, albeit at a very similar level in August. Our methods estimate 40,303 tonnes of British bird biomass in August, excluding the Common Pheasant and Redlegged Partridge, compared to 29,510 tonnes of nongamebird biomass in April. Biomass then drops from this late summer peak as mortality removes individuals and the remaining summer migrants depart, although these losses are largely offset by the arrival of a substantial number (and hence biomass) of winter migrants in September and October (Fig. 3a).

The great majority of the August non-gamebird biomass comprises British resident species (37,984 tonnes; 94\%), with most of the rest contributed by undeparted summer migrants (1595 tonnes; 4\%). August non-gamebird biomass is approximately double the estimate of non-gamebird breeding biomass from APEP4 (40,303 vs 19,870 tonnes), and approximately a third as much again as the estimated total non-gamebird biomass in April (40,303 vs 29,510 tonnes). We estimate that biomass declines from August through winter due to adult and juvenile mortality, reaching its minimum again in April as the populations of many winter visitors depart and prior to production of the summer's juvenile recruits (Fig. 3a).

Populations of non-native galliforms are estimated to comprise $52.5 \%$ of the biomass of birds in Britain in August, with $3.7 \%$ of biomass in Red-legged Partridges (3131 tonnes), and 48.8\% in Common Pheasants (41,364 tonnes) (Fig. 3b; Table 1). Thus, only $47.5 \%$ of British bird biomass in August relates to species other than these two non-native galliforms. After the Common Pheasant, the greatest biomass is present in the Woodpigeon (Fig. 4). Other British bird species with high August biomass include the Canada 

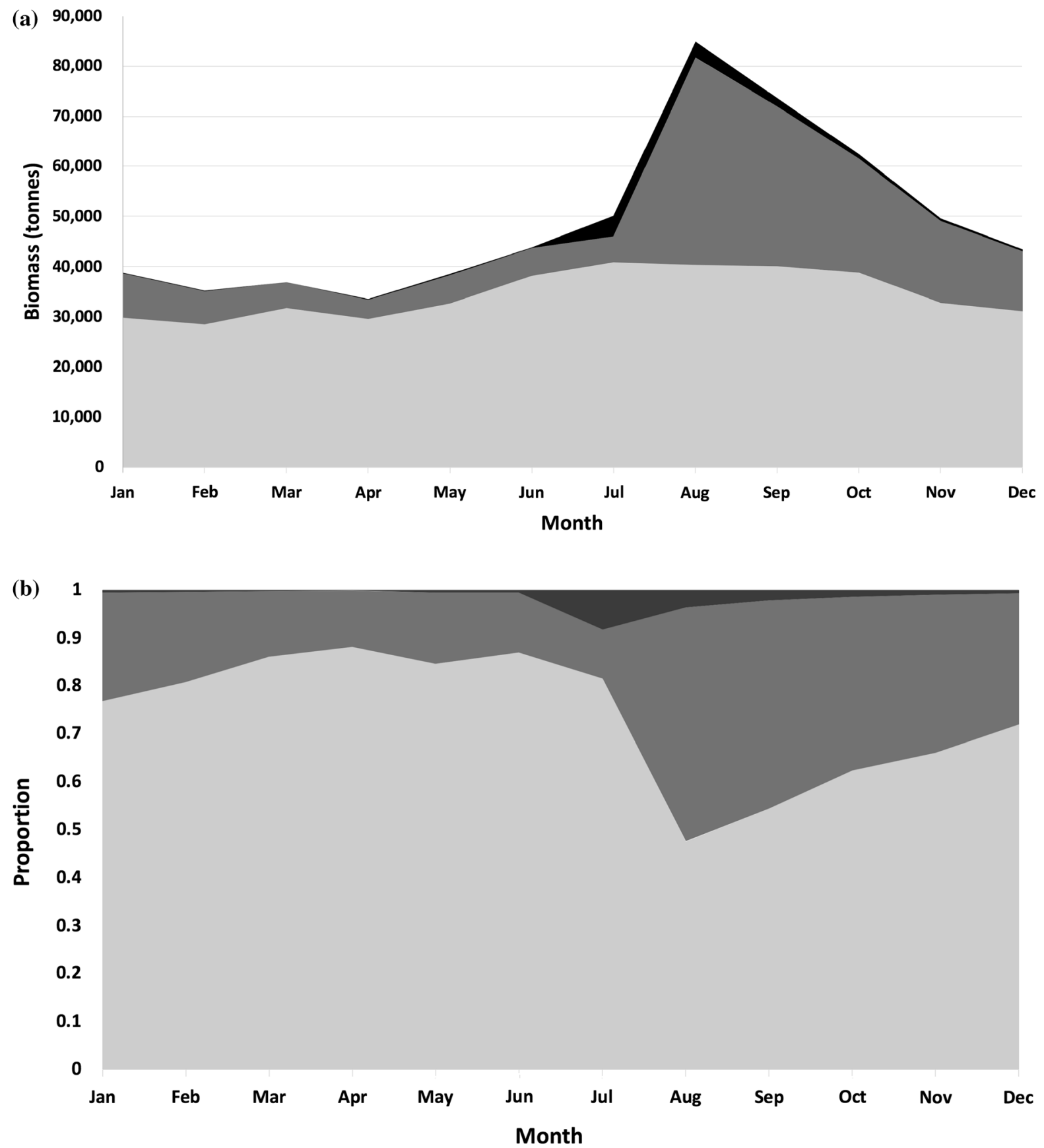

Fig. 3 Annual variation in (a) the total biomass of British bird species (tonnes), with Red-legged Partridge (Alectoris rufa) in black, Common Pheasant (P. colchicus) biomass in grey, and all other species combined in pale grey; and $\mathbf{b}$ the proportion of

Goose, Greylag Anser anser and Rock Dove/Feral Pigeon Columba livia, where many or all of the individuals are of captive ancestry, and the Red
British bird biomass contributed by the Red-legged Partridge (black), Common Pheasant (grey), and all other species combined (light grey)

Grouse Lagopus lagopus, the population of which is in part managed for hunting (Fig. 4). Seabirds also contribute substantial biomass at this time of year 
Table 1 Variation in the total and percentage (of the total across all British birds) biomass of Common Pheasants (CP) and Red-legged Partridges (RLP) in August, and the percentage of the annual British bird biomass summed across all species and all months for these two species (Ann. \%CP, Ann \%RLP), for different estimates of the numbers of birds released (Release size). GWCT $=$ the estimates from GWCT (2018) on

\begin{tabular}{lcccccc}
\hline Release size & Total CP & Total RLP & \%CP & \%RLP & Ann. \%CP & Ann. \%RLP \\
\hline GWCT & 41,364 & 3131 & 48.8 & 3.7 & 27.9 & 2.0 \\
Low estimate & 13,313 & 529.7 & 24.6 & 1.0 & 16.3 & 0.6 \\
High estimate & 53,264 & 4481 & 54.3 & 4.6 & 31.6 & 2.5 \\
\hline
\end{tabular}

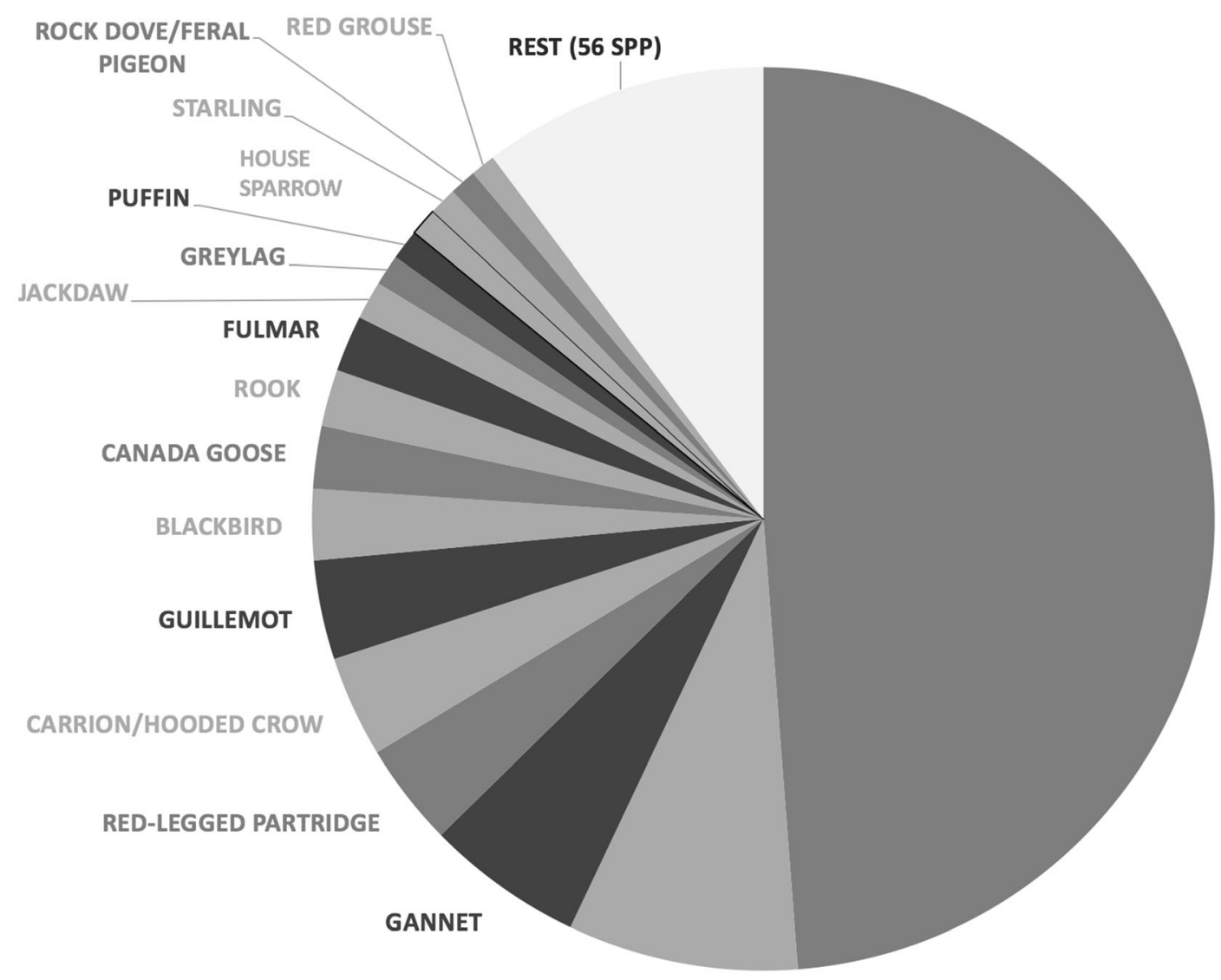

PHEASANT

\section{WOODPIGEON}

Fig. 4 The proportion of British bird biomass in August contributed by the 73 species in our analysis present in that month, with the seventeen species with the highest biomass identified individually, and the contribution of the remaining 56 species combined. Dark grey segments and names are seabirds,

(13.3\% of the total) - notably the Gannet Morus bassanus, Guillemot Uria aalge, Fulmar Fulmarus glacialis and Puffin Fratercula arctica-albeit that which we base most of our analyses: 43 million Common Pheasants and 8.9 million Red-legged Partridges. Low estimates are 10 million Common Pheasants and 1 million Redlegged Partridges released; high estimates are 57 million and 10 million, respectively. Total biomass estimates are in tonnes. See Methods for data sources 
also present in four species of corvid-Carrion/ Hooded Crow Corvus corvus/cornix, Rook C. frugilegus and Jackdaw C. monedula (Fig. 4). The top 17 species ranked by August biomass (those depicted in Fig. 4) constitute $89.8 \%$ of the total from the 73 species in our analysis present that month, while the top half (36 species) constitute more than $99 \%$.

We estimate Red-legged Partridge and Common Pheasant biomass to drop rapidly from their autumn peaks, but these two species still comprise $12 \%$ of the British bird biomass in April (Fig. 3b), at which point we assume that populations have dropped to the levels the previous April through shooting or other sources of mortality (with mortality in the breeding population replaced from surviving released birds and reproduction in the wild for the Common Pheasant, and reproduction in the wild in the Red-legged Partridge). Summing our estimates across the entire year, around $27.9 \%$ of the biomass across all British bird species in our analysis is contributed by Common Pheasants, and around $2 \%$ by Red-legged Partridges (Table 1).

The outcomes of re-running our analyses using minimum and maximum likely estimates for the numbers of Common Pheasants and Red-legged Partridges released each year are shown in Table 1. The lower estimates of release sizes result in Common Pheasants comprising around a quarter of total bird biomass in August, or just over 13,000 tonnes. This rises to just over 54\% August bird biomass (over 53,000 tonnes) using the high release size estimates (Table 1). The amount of August bird biomass in Redlegged Partridges varies from 1 to $4.6 \%$ of the total across all species. Summed across the year, varying estimates of release size suggest that $16-31.6 \%$ of the biomass across all British bird species in our analysis is contributed by Common Pheasant, and $0.6-2.5 \%$ is Red-legged Partridge (Table 1).

\section{Discussion}

Estimates of the contribution of gamebirds to overall avian biomass have played a significant role in debates around their likely ecological impacts in the U.K. (Larkman et al. 2015; Blackburn and Gaston 2018; Avery 2019; Pringle et al. 2019). However, to date, these calculations have been constrained by the lack of information on how that overall biomass changes through the year. The results reported here suggest that the biomass contribution of non-native galliforms is at its lowest during the breeding season, and at its highest in August following the release of many millions of captive reared birds.

The calculations presented here inevitably make a number of simplifying assumptions. The key issue is whether these are likely to invalidate the broad dynamic of the contribution of non-native galliforms to overall avian biomass that is observed. First, we only calculate annual variation in biomass for 81 of the 253 species breeding or wintering in Britain as listed by APEP4 (Woodward et al. 2020). This sample comprises 50 resident species, 6 summer migrants, and 25 species that are mainly or entirely winter visitors to Britain. This means that we inevitably underestimate the contribution of species other than Common Pheasant and Red-legged Partridge to the biomass in any given month. However, the magnitude of this underestimate is likely to be negligible. The 81 species represent $93.4 \%$ of the total British bird breeding biomass, as calculated from the numbers in APEP4: most of the biomass of the assemblage of birds present in Britain is contributed by a few abundant species (Fig. 2), while most British bird species provide a tiny fraction of the total. While we only include 6 summer migrant species, summer migrants contribute less than $5 \%$ of breeding biomass, and our sample captures $73 \%$ of that.

The extent to which our sample of 81 species means that we underestimate bird biomass through the autumn and winter months is less clear, as there are not independent estimates of winter biomass for most British bird species. Nevertheless, the numbers in APEP4 suggest that any underestimates will again be small. Most of the migrant species with large winter biomasses are included in our analyses (82\% of the total biomass for species with separate winter population estimates in APEP4). Moreover, most winter biomass is likely to come from resident species. For scale, the breeding populations of British resident birds total more than 140 million individuals, while the winter population sizes of species that are primarily or entirely winter visitors, and have separate winter population estimates in APEP4, sum to less than 10 million. If we assumed that the winter population sizes of resident species were equal to their breeding population sizes, then residents would contribute 93.5\% of the individuals in the British winter bird assemblage, and $83.5 \%$ of the biomass. In practice, the 
winter population sizes of resident species will be larger, due to the presence of large numbers of immature birds. Thus, the fact that our sample captures most breeding bird biomass suggests that it will also capture most wintering bird biomass. If we assumed that $10 \%$ of British bird biomass was consistently omitted from our sample, the two introduced galliforms would together still comprise half of August bird biomass, all other assumptions remaining the same. Their overall annual contribution to British bird biomass would drop from 30 to $28 \%$, using the GWCT (2018) figures on number of birds released.

Second, we assumed that bird population sizes are stable from year to year. This is a reasonable assumption for the snapshot of intra-annual biomass variation presented here. In practice, various trend indicators suggest that, while there are "winners" and "losers" in terms of population changes in response to current environmental changes, the overall British avifauna is decreasing in numbers. However, the decrease in any one year will be tiny relative to the total. Conversely, the numbers of gamebirds released has been on an upward trajectory for many years (Robertson et al. 2017), representing an increasing proportion of British bird biomass.

Third, we make various simplifying assumptions about how migration adds and removes birds from the British assemblage over the course of the year. For the most part, we assumed that summer migrants arrived in April and left in September, while winter migrants arrived in September and left in March. These assumptions are crude, especially for the arrival of winter migrants: these species are likely to be more variable and spread out temporally in their appearance in Britain, being less constrained by the demands of a limited period available for breeding, and more driven by weather outside Britain. Our simplifications were intended to offset the fact that there is little firm information on the numbers of pure migrant birds in autumn, which pass through Britain but neither breed nor winter here. In fact, while bird migration is one of the most impressive wildlife events in Britain, the biomasses involved are relatively small in comparison to that of resident birds. The data in APEP4 (Woodward et al. 2020) show that $93 \%$ of British bird breeding biomass comes from resident species, and as discussed above, similar figures probably pertain for the winter bird assemblage. Moreover, while some British resident species exchange individuals with continental populations in spring and autumn (e.g. Robin Erithacus rubecula, Blackbird Turdus merula, Song Thrush Turdus philomelos), the numbers involved are actually relatively small compared to their total British populations (Wernham et al. 2002; Balmer et al. 2013). Thus, different assumptions about migrant populations would make little change to our overall biomass figures, perhaps shifting a few percentage points to earlier or later months.

Fourth, we make various simplifying assumptions about how births and deaths vary across the year. We assume that adult mortality data from the British Trust for Ornithology website are accurate but that adults die evenly across the year, and that juvenile recruitment replaces this mortality at the end of the period of immaturity. Although data on juvenile mortality rates were also available for most species, the available adult and juvenile mortalities did not easily combine to maintain a constant breeding population size; sometimes our assumed juvenile mortality rates were very similar to the BTO estimates (e.g. 0.19 vs 0.177 for Marsh Tit Poecile palustris), but other times they differed substantially (e.g. 0.59 vs 0.148 for Willow Tit P. montanus). We assumed that fledglings are added to the population depending on data from the literature on the average number, duration, and fledging success of breeding attempts for each species, and die at an exponential rate. We do not count nestlings in biomass estimates. Changes to the adult mortality assumptions would alter the annual distribution of biomass more than it would the total amount: for example, adults may survive better over summer and worse through winter than we assume, which would increase the biomass peak in August somewhat, but lead to a steeper decline from there to the start of the breeding season. Changes to the birth and juvenile mortality assumptions could lead to dramatically greater biomass in Britain in late summer and autumn, especially if fledging success is much higher in reality. However, our approach produces very similar biomasses to the "Post-Breeding Index" (PBI) of Larkman et al. (2015), which they used to estimate autumn biomass for a range of farmland bird species based on population size, number of broods per year and fledging success. Applying their equation and data sources to the six species in both their and our data produces a close correlation between our August and their PBI biomass estimates (slope $=0.95 \pm 0.04$, $\mathrm{r}^{2}=0.99$ ), with an intercept value that does not differ 
statistically from zero $(\mathrm{t}=1.67, \mathrm{p}=0.17)$. Moreover, doubling the number of juvenile birds present in August in all breeding species except Common Pheasant and Red-legged Partridge would be unlikely to add more than a third to the total biomass of other species, given the presence of adults and summer migrants in August. Even had we underestimated productivity to this degree, the two non-native gamebird species would still contribute more than $40 \%$ of the bird biomass in Britain in August.

Overall, therefore, while we base our biomass estimates on only a sample of the British avifauna, and make very crude assumptions about the fundamental population dynamic parameters of birth, death, immigration and emigration, it is unlikely that realistic changes to our assumptions about native populations would greatly alter our primary conclusion: the biomass of the two non-native galliform species present in August is roughly equal to the biomass of all other species in the British bird fauna at that time (Fig. 4). Far larger effects are likely to arise from our assumptions about these gamebirds, especially the numbers of birds released in late summer. Incorporating reasonable uncertainty in these numbers suggests that non-native gamebird biomass could be as low as one quarter of the August total, or as high as $60 \%$. Even the low estimate is still a striking proportion of the total, however. We estimate Red-legged Partridge and Common Pheasant biomass to drop rapidly from this late summer peak, but these two species still comprise $12 \%$ of the British bird biomass in April (Fig. 3b). Summing across the year, and accounting for the fact that we do not include estimates from all British bird species, it is probably reasonable to say that Common Pheasant and Red-legged Partridge contribute around a quarter of British bird biomass. This may be an underestimate, because most Common Pheasants are released before August (whereas we assume they are not), and so will also contribute dramatically to mid-summer bird biomass. The obvious question is then what this means in terms of the ecological impacts of these species.

The primary impacts of non-native galliforms on the British environment are likely to come through their consumption of resources that would otherwise be available to native species, their provision of a resource for consumption by native predators, and management decisions taken by landowners to benefit these species. Common Pheasants and Red-legged
Partridges undoubtedly provide an enormous resource for predators, but this may be a resource that would largely be replaced by native species biomass in their absence. If this latter point is true, however, then it follows that Common Pheasants and Red-legged Partridges are likely to be having effects through their consumption of resources that would otherwise be available to those native species: if they are not a significant extra resource for predators, then they ought to be a significant drain on resources for other consumers (or both). However, the situation here is complicated by the fact that shooting estates and farmers provide supplementary food for these nonnative galliforms (primarily seeds), in many cases beyond the shooting season and into spring, with the amount spent on this food in 2004 ( $£ 33$ million) then buying the equivalent of 450,000 tonnes of wheat (Larkman et al. 2015). They also manage habitat to benefit these species (game cover crops), and control predator numbers. These management actions may improve the general environment for native species as well as non-natives. A large body of work has explored these various effects (see reviews in Larkman et al. 2015; Avery 2019; Madden and Sage 2020; Mason et al. 2020), but their net consequences for the British environment currently remain unclear.

The fundamental question we need to ask is what would be the response of the native bird (and other) assemblages to an environment without Common Pheasants or Red-legged Partridges, and the manipulation of the environment that their presence entails? Unfortunately, since non-native galliforms are widespread and abundant in suitable environments across Britain, their net impact is likely to remain difficult to assess without large-scale removal experiments. Local-scale responses are dependent to a significant degree on their macroecological context, and so smallscale, short-term Common Pheasant exclusion experiments in a wider landscape where Pheasants are an abundant species will not quantify their effect. If the common assumption that avian assemblage structures are resource-limited pertains, and unless the management of the environment for gamebirds removes this constraint, then this abundance will be at the expense of other species.

Acknowledgements We thank Jo Madden for providing the motivation to conduct this analysis, and Richard Gregory, Jo 
Madden and two anonymous reviewers for their helpful comments on earlier versions of the manuscript.

Author contributions TMB and KJG conceived the research and wrote the manuscript. TMB compiled and analysed the data.

Funding This research was not supported by any funding agency.

Availability of data and material Data are either published or available in Appendix A.

\section{Compliance with ethical standards}

Conflict of interest The authors have no conflicts of interest to declare that are relevant to the content of this article.

Open Access This article is licensed under a Creative Commons Attribution 4.0 International License, which permits use, sharing, adaptation, distribution and reproduction in any medium or format, as long as you give appropriate credit to the original author(s) and the source, provide a link to the Creative Commons licence, and indicate if changes were made. The images or other third party material in this article are included in the article's Creative Commons licence, unless indicated otherwise in a credit line to the material. If material is not included in the article's Creative Commons licence and your intended use is not permitted by statutory regulation or exceeds the permitted use, you will need to obtain permission directly from the copyright holder. To view a copy of this licence, visit http://creativecommons.org/licenses/by/4.0/.

\section{References}

Aebischer NJ (2019) Fifty-year trends in UK hunting bags of birds and mammals, and calibrated estimation of national bag size, using GWCT's National Gamebag census. Eur J Wildl Res 65:64-77

Avery M (2019) The common pheasant: its status in the UK and the potential impacts of an abundant non-native. Brit Birds 112:372-389

Baillie SR et al. (2009) Breeding birds in the wider countryside: their conservation status 2008 BTO research Report No 516. British Trust for Ornithology, Thetford

Balmer DE et al (2013) Bird Atlas 2007-11: the breeding and wintering birds of Britain and Ireland. BTO Books, Thetford, Ann Arbor

Blackburn TM, Gaston KJ (2018) Abundance, biomass and energy use of native and alien breeding birds in Britain. Bio Invasions 20:3563-3573

Blackburn TM, Bellard C, Ricciardi A (2019) Alien versus native species as drivers of recent extinctions. Front Ecol Environ 17:203-207

Cameron EK, Vilà M, Cabeza M (2016) Global meta-analysis of the impacts of terrestrial invertebrate invaders on species, communities and ecosystems. Global Ecol Biogeogr 25:596-606
Capstick LA, Sage RB, Hoodless A (2019) Ground flora recovery in disused pheasant pens is limited and affected by pheasant release density. Biol Conserv 231:181-188

Cramp S (ed) (1985) Birds of the western Palaearctic. Volume IV. Terns to woodpeckers. Oxford University Press, Oxford

Cramp S (ed) (1988) Birds of the western Palaearctic. Volume V. Tyrant flycatchers to thrushes. Oxford University Press, Oxford

Cramp S (ed) (1992) Birds of the Western Palaearctic. Volume VI. Warblers. Oxford University Press, Oxford

Cramp S, Perrins CM (eds) (1993) Birds of the Western Palaearctic. Volume VII. Flycatchers to shrikes. Oxford University Press, Oxford

Cramp S, Perrins CM (eds) (1994a) Birds of the Western Palaearctic. Volume VIII. Crows to finches. Oxford University Press, Oxford

Cramp S, Perrins CM (eds) (1994b) Birds of the Western Palaearctic. Volume IX. Buntings and New World warblers. Oxford University Press, Oxford

Cramp S, Simmons KEL (eds) (1977) Birds of the Western Palaearctic. Volume I. Ostrich to ducks. Oxford University Press, Oxford

Cramp S, Simmons KEL (eds) (1980) Birds of the Western Palaearctic. Volume II. Hawks to bustards. Oxford University Press, Oxford

Cramp S, Simmons KEL (eds) (1983) Birds of the Western Palaearctic. Volume III. Waders to gulls. Oxford University Press, Oxford

Dunning JB Jr (2007) CRC handbook of avian body masses, 2nd edn. CRC Press, Boca Raton

Gaertner M et al (2014) Invasive plants as drivers of regime shifts: identifying high-priority invaders that alter feedback relationships. Divers Distrib 20:733-744

Gallardo B et al (2016) Global ecological impacts of invasive species in aquatic ecosystems. Global Change Biol 22:151-163

Game and Wildlife Conservation Trust (GWCT) (2018) How many birds are shot in the UK? Game Wildl Rev 2017:41-42

Gaston KJ, Blackburn TM (2000) Pattern and process in macroecology. Blackwell Science, Oxford

Holt RD et al (2010) Disturbance of lekking Lesser PrairieChickens (Tympanuchus pallidicinctus) by Ring-Necked Pheasants (Phasianus colchicus). Western N Am Nat 70(2):241-244

Larkman A et al (2015) Small farmland bird declines, gamebird releases, and changes in seed sources. In: Macdonald DW, Feber RE (eds) Wildlife conservation on farmland Volume 2. Oxford University Press, Oxford, pp 181-202

Lever C (2005) Naturalised birds of the world. T \& AD Poyser, London

Madden JR, Hall A, Whiteside MA (2018) Why do many pheasants released in the UK die, and how can we best reduce their natural mortality? Eur J Wildl Res 64(4):40

Madden JR, Sage RB (2020) Ecological consequences of gamebird releasing and management on lowland shoots in England: a review by rapid evidence assessment for natural England and the British Association of shooting and conservation. Natural England Evidence Review NEER016. Natural England, Peterborough 
Mason LR, et al (2020) The impacts of non-native gamebird release in the UK: an updated evidence review. RSPB Research Report No. 66. RSPB Centre for Conservation Science, Sandy, UK

Musgrove AJ et al (2013) Population estimates of birds in Great Britain and the United Kingdom. Brit Birds 106:64-100

Neumann JL et al (2015) Releasing of pheasants for shooting in the UK alters woodland invertebrate communities. Biol Conserv 191:50-59

Pressland CL (2009) The impact of releasing pheasants for shooting on invertebrates in British woodlands. $\mathrm{PhD}$ thesis, University of Bristol

Pringle $\mathrm{H}$ et al (2019) Associations between gamebird releases and generalist predators. J Appl Ecol 56:2102-2113

Pyšek P et al (2012) A global assessment of invasive plant impacts on resident species, communities and ecosystems: the interaction of impact measures, invading species' traits and environment. Global Change Biol 18:1725-1737

Pyšek P et al (2020) Scientists' warning on invasive species. Biol Rev 95:1511-1534. https://doi.org/10.1111/brv. 12627

Robertson P (1991) Estimating the nesting success and productivity of British pheasants Phasianus colchicus from nest-record schemes. Bird Study 38(2):73-79

Robertson P et al (2017) Pheasant release in Great Britain: longterm and large-scale changes in the survival of a managed bird. Eur J Wildl Res 63:100

Robinson RA (2005) BirdFacts: profiles of birds occurring in Britain \& Ireland (BTO Research Report 407). BTO, Thetford (http://www.bto.org/birdfacts, Accessed on 15 May 2020)
Sage RB et al (2002) The effect of an experimental infection of the nematode Heterakis gallinarum on hand-reared grey partridges Perdix perdix. Parasitol 124:529-535

Sage RB, Ludolf C, Robertson PA (2005) The ground flora of ancient seminatural woodlands in pheasant release pens in England. Biol Conserv 122:243-252

Siriwardena GM et al (2000) The importance of variation in the breeding performance of seed-eating birds in determining their population trends on farmland. J Appl Ecol 37(1):128-148

Storchová L, Horák D (2018) Life history characteristics of European birds. Global Ecol Biogeogr 27:400-406

Tompkins DM et al (2000) The role of shared parasites in the exclusion of wildlife hosts: Heterakis gallinarum in the ring-necked pheasant and the grey partridge. J Anim Ecol 69:829-840

Vilà M et al (2011) Ecological impacts of invasive alien plants: a meta-analysis of their effects on species, communities and ecosystems. Ecol Lett 14:702-708

Vilà M, Hulme PE (eds) (2017) Impact of Biological Invasions on Ecosystem Services. Springer, Berlin

Wernham CV et al (eds) (2002) The migration atlas: movements of the birds of Britain and Ireland. T \& AD Poyser, London

Woodward I et al (2020) Population estimates of birds in Great Britain and the United Kingdom. Brit Birds 113:69-104

Publisher's Note Springer Nature remains neutral with regard to jurisdictional claims in published maps and institutional affiliations. 